\title{
Adhesion of diamond film on functionally gradient WC-10wt. \%Co hardmetal
}

\author{
Yigao YUAN ${ }^{1, a}$, Jianpeng $\mathrm{LI}^{1, \mathrm{~b}}$, Weiquan $\mathrm{SUN}^{2, \mathrm{c}}$ \\ ${ }^{1}$ College of Mechanical Engineering, Donghua University, 201620, Shanghai, China \\ ${ }^{2}$ Shanghai tool works Co., Ltd, 200093, Shanghai, China \\ aemail: yuanyg@dhu.edu.cn, bemail: leejp@hotmail.com, `email: sunweiquan@stwc.cn
}

\section{Keywords: Functionally gradient WC-Co; Diamond film; Adhesion; Hot filament CVD}

\begin{abstract}
Diamond coated tools of cemented carbide substrate with high Co content are extremely useful for machining difficult-to-cut materials. However, it is very difficult to deposit a well-adherent diamond coating on WC-Co with high Co content because of the strong catalytic effect of Co. In this work, a new functionally gradient WC-10wt. \%Co hardmetal not containing $\eta$ phase with a Co-depleted surface layer was fabricated. Diamond film was deposited on the gradient WC-10 wt. \%Co by the hot filament chemical vapor deposition technique, and the quality and adhesion of diamond film were evaluated. The results indicate that the functionally gradient WC-10 wt. \%Co hardmetal shows high adhesion strength to the diamond coating, and is a very promising substrate material for producing diamond coated tools.
\end{abstract}

\section{Introduction}

Diamond coatings, prepared by chemical vapor deposition (CVD) techniques, can increase significantly the lifetime of WC-Co cemented carbide tools, applied for machining difficult-to-cut materials such as aluminium-based composites, graphite, ceramics and carbon fiber-reinforced composites [1-4]. However, it is very difficult to deposit a well-adherent diamond coating on the cemented carbide substrates. The reason for this is that, during the initial diamond nucleation process, the presence of the Co binder in the cemented carbide substrates strongly inhibits the growth of diamond and promotes the formation of the non-diamond phases at the diamond-carbide interface, leading to poor adhesion [5]. Reducing the deleterious effect of cobalt on diamond deposition, therefore, is essential for improving the adhesion between diamond coatings and WC-Co substrates.

To improve the adhesion, numerous pretreatment procedures prior to diamond deposition, including selective chemical etching [6,7], formation of stable Co compound [8-10] and deposition of intermediate layers [11-14], have been developed over the past decades to avoid the contact of the Co phase to the diamond. Among them, selective removal of Co on WC-Co tool surface by chemical etching is the most widespread technique in industry. With selective chemical etching techniques to remove surface cobalt, however, there is a risk of forming subsurface porosity in the WC-Co substrates, especially in the WC-Co with high Co content (Co $\geqslant 6$ wt. $\%)$, this will weaken the bonding of the subsurface WC particles and lead to flaking in interrupted cutting operations. The formation of an intermediate layer prior to coating serves two purposes: (1) relief of residual stresses at the diamond-carbide interface, and more importantly (2) formation of a diffusion barrier between the cobalt and the diamond coating. Several PVD layers, such as TiN, CrN and NbC, have been shown to be effective in improving the adhesion of diamond coatings, but the introduction of intermediate layers will lower diamond nucleation rates as well as lower diamond growth rates. Additionally, the question of diamond layer adhesion on the various intermediate layers has not yet been solved [15].

Besides pretreatment procedures mentioned above, the Co-depleted surface can also be achieved via preparation of functionally graded cemented carbides. In 1980s, Sandvick developed a functionally graded cemented carbide with graded Co composition (so-called DP carbide), Which 
had a surface region with low Co content, a thin subsurface region with high Co content, and a core region with $\eta$-phase $\left(\mathrm{Co}_{3} \mathrm{~W}_{3} \mathrm{C}\right)$ and nominal Co content [16]. Detailed studies of the growth of diamond coatings revealed that DP carbide can effectively improve the interfacial adhesion [17], but DP carbide is not suitable for producing diamond coated tools, owing to the presence of the very brittle core comprising much $\eta$-phase, which is detrimental to the mechanical properties of the WC-Co materials.

Recently, a new functionally gradient WC-Co hardmetal with a Co-depleted surface layer has been developed by Fan Peng et al [18]. Unlike in the DP carbide, no brittle $\eta$-phase exists in this material. Such a hard-surface, tough-core structure combines high wear resistance and high fracture toughness in a single component, has been found to be able to offer superior mechanical properties in comparison to conventional homogeneous WC-Co materials [19], and has the strong potential to significantly improve the durability and reliability of industrial tools. In the present study, the diamond film was deposited on the functionally gradient WC-Co, and the quality and adhesion of diamond film were evaluated by means of scanning electron microscopy, Raman spectroscopy and indentation test. The purpose of work is to prove the feasibility of using functionally gradient WC-Co as substrates for diamond coating.

\section{Experimental}

\section{Materials and sample preparation}

At present, diamond coating is usually deposited on cemented carbide tools with low Co content (Co $\leq 6$ wt. \%). However, WC-Co tools with high Co content ( $\mathrm{Co} \geq 6$ wt. \%) are more widely used in difficult-to-cut materials machining due to their higher strength and better ductility. Moreover, compared to conventional microstructured WC-Co, ultrafine-grained WC-Co composites (in which mean grain size of $\mathrm{WC} \leq 0.6 \mu \mathrm{m}$ ) possess superior combinations of hardness and transverse rupture strength. Considering the above, the WC-Co cemented carbides with $0.4 \mu \mathrm{m}$ WC particle sizes and $10 \mathrm{wt} . \%$ cobalt contents were selected as the substrates for this study.

The functionally gradient WC-10 wt.\% Co composites (labeled as gradient WC-10Co) were fabricated via the carburization of pre-sintered WC-10Co specimens with sub-stoichiometric carbon content (about 5.36 wt.\%), which have no $\eta$-phase after conventional sintering but closing to the border with the $\eta$-phase formation according to the WC-Co phase diagram. The fabrication process was described by the present authors in Ref. [20, 21] in detail. For comparison, a conventional homogeneous WC-10 wt. \% Co cemented carbide with $0.4 \mu \mathrm{m}$ WC particle sizes (labeled as conventional WC-10Co) was used as the reference material.

Prior to pretreatment, a part of gradient and conventional WC-10Co specimens both with dimensions of $5 \times 6 \times 20 \mathrm{~mm} 3$ were cut in the cross section by using electrical discharge machining (EDM), in order to measure the Co concentration profiles in samples after and before pretreated. The sintered surfaces of the remaining samples were first mechanically polished with $10 \mu \mathrm{m}$ diamond pastes, then ultrasonically cleaned with acetone and finally pretreated to deposit diamond. The pretreatment of samples was conducted by using the two-step etching process, namely, etching by using Murakami's reagent $\left(\mathrm{K}_{3} \mathrm{Fe}(\mathrm{CN})_{6}: \mathrm{KOH}: \mathrm{H}_{2} \mathrm{O}=1: 1: 10\right)$ for $30 \mathrm{~min}$ in an ultrasonic vessel to rough the WC surface, and etching in Caro's acid $\left(\mathrm{H}_{2} \mathrm{SO} 4: \mathrm{H}_{2} \mathrm{O}_{2}=1: 10\right)$ for 1 min to remove Co phase on the surface. After etching, samples were ultrasonically rinsed with de-ionized water and dried with nitrogen gas.

\section{Diamond deposition}

The diamond coating was synthesized by the hot filament chemical vapor deposition (HFCVD) technique. The reaction gases were $\mathrm{H}_{2}$ and acetone. The tantalum wires were used as the hot filaments. During the deposition, the temperatures of hot filaments and the substrate surfaces were $2000 \pm 200 \mathrm{C}$ and $900 \pm 100 \mathrm{C}$, respectively. A negative bias was applied to the substrate for enhancing the diamond nucleation density. The detailed deposition parameters are shown in Table 1. 
Table 1 Detailed parameters of diamond deposition.

\begin{tabular}{cc}
\hline Carbon source & Acetone \\
Hydrogen flow, sccm & 200 \\
Pressure, Torr & $10-30$ \\
Filament temperature, C & $2000 \pm 200$ \\
Substrate temperature, C & $900 \pm 100$ \\
Deposition time, $\mathrm{h}$ & 6 \\
\hline
\end{tabular}

\section{Characterization and analysis techniques}

The cobalt concentration profiles of both gradient WC-10Co and conventional WC-10Co after and before etched were measured using an energy dispersive X-ray spectroscopy (EDS, Oxford). Measurements of Co content were examined as a function of depth perpendicular to the surface of polished cross-sections of samples. Each data point of the Co composition is an averaged value obtained by scanning a $10 \times 60 \mu \mathrm{m}^{2}$ rectangular area that was parallel to the surface of the sample. The rectangular area for measurement was spaced at $10 \mu \mathrm{m}$ increments in the direction perpendicular to the original surface.

The surface morphology of diamond coatings was investigated using a field emission scanning electron microscopy (FE-SEM, Hitachi S4800). The phase composition and the residual stress of diamond coatings were assessed by micro-Raman spectroscopy (Renishaw, InVia-Reflex). The light source was an argon ion laser with a wavelength of $514.5 \mathrm{~nm}$. Additionally, in order to evaluate qualitatively the adhesion of diamond coatings on the substrates, Rockwell indentation tests were conducted using a Rockwell hardness tester with a diamond indenter having a cone of $120^{\circ}$ and a tip radius of $0.2 \mathrm{~mm}$. Each deposited sample was tested by applying a load of $980 \mathrm{~N}$ at the diamond indenter.

\section{Results}

The measured Co concentration profiles of both gradient WC-10Co and conventional WC-10Co after and before etched are shown in Fig.1. Clearly, before etching there is a continuous Co gradient as a function of the depth in the gradient WC-10Co, the Co content of the surface zone is reduced to 5.84 from about $10 \mathrm{wt} . \%$. Deeper into the specimen, the Co content gradually reaches the nominal Co content. In contrast, conventional WC-10Co is homogeneous, the Co content profile is thus flat (as shown in Fig.1a).

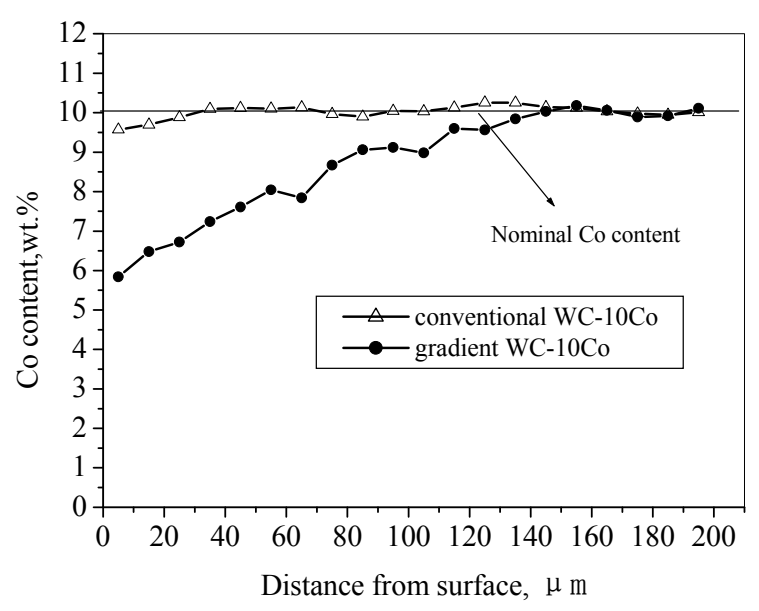

(a)

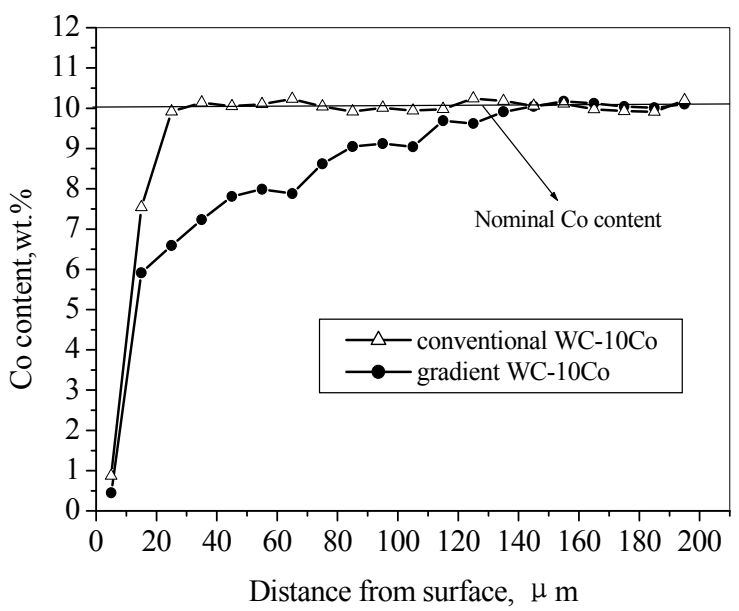

(b)

Fig.1 EDS profiles of the Co concentration measured in the samples, (a) before and (b) after etched.

Fig. $1 \mathrm{~b}$ shows the Co content distribution in two substrates pretreated with chemical etching. It can be seen that etching depth was about 15 and $25 \mu \mathrm{m}$ in the chemically etched gradient and conventional WC-10Co substrates respectively, and surface Co content of both samples decreases significantly. After etching, the Co content in surface layer of gradient WC-10Co decreased from 
5.84 to 0.45 wt. $\%$, while that of conventional WC-10Co decreased from about 10 to 0.87 wt.\%. These suggest that the Co phase can be almost completely removed from the surface of both gradient WC-10Co and conventional WC-10Co by the two-step pretreatment. However, the etching depth and the Co contents in surface layer of different substrates after etched, under same pretreatment condition, are obviously different. Compare with the conventional WC-10Co, the etching depth and the Co content in surface layer of gradient WC-10Co etched are lower.

The SEM images of the surface morphology of diamond films deposited on different substrates are given in Fig.2. Fig.2a displays that the surface of conventional WC-10Co is covered by a continuous layer of microcrystalline diamond films, and diamonds are equiaxed and well-crystallized. The surface of gradient WC-10Co shown in Fig.2b, exhibit the similar morphology to the conventional one. It indicates that the diamond films on the substrates of both gradient $\mathrm{WC}-10 \mathrm{Co}$ and conventional $\mathrm{WC}-10 \mathrm{Co}$ have a good crystalline form and dense structure without local flaking. However, the mean grain sizes of diamonds grown on different substrates are different. The measurement results of diamonds grain sizes indicate that the mean grain sizes of diamonds grown on the conventional WC-10Co are slightly larger than that on the gradient WC-10Co.

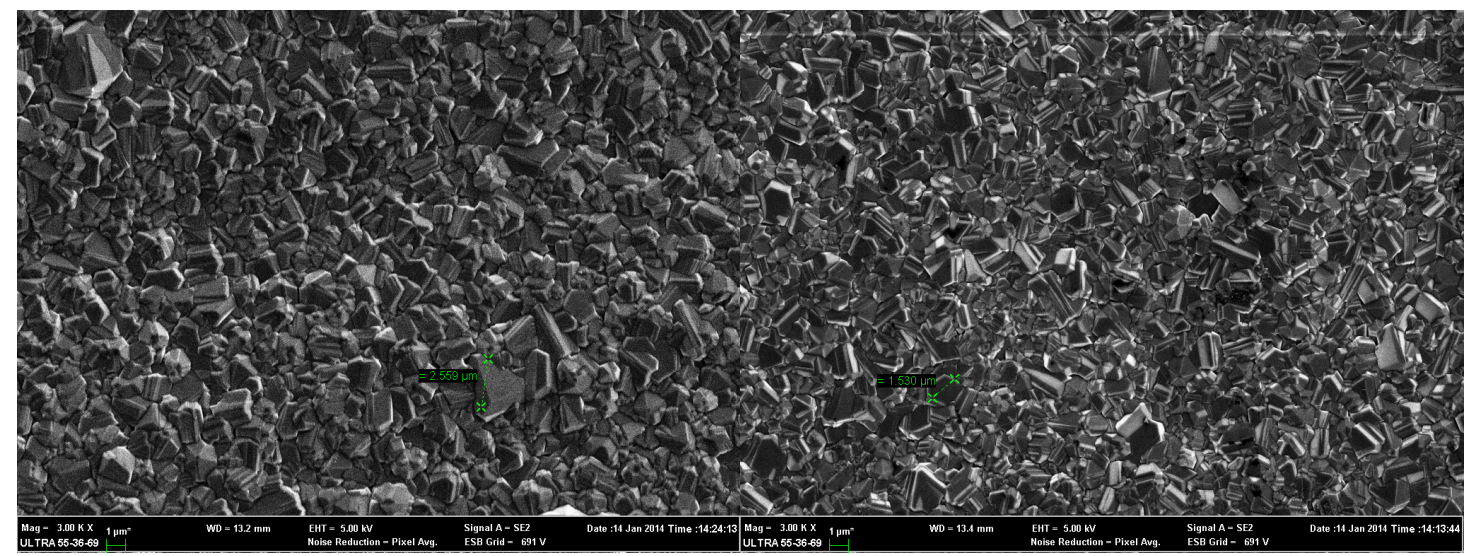

(a)

(b)

Fig.2 SEM surface images of diamond films grown for $6 \mathrm{~h}$ on different substrates pretreated with chemical etching. (a) conventional WC-10Co and (b) gradient WC-10Co.

In order to assess the quality of as-fabricated diamond films, Raman spectroscopy is employed. Fig. 3 shows the Raman spectra of the diamond films grown on different substrates. It is found that the peak around $1332 \mathrm{~cm}-1$ indicative of the sp3 bonding of diamond is visible for all the films [22]. From this figure, it can be seen that the Raman bands are present as $1338.2,1336.4 \mathrm{~cm}-1$ in diamond films deposited on conventional and gradient WC-10Co substrates, respectively. A sharp diamond characteristic peak around $1332 \mathrm{~cm}^{-1}$ and a weak graphite (bands) peak at $1550 \mathrm{~cm}^{-1}$ are obviously observed, which indicates that the deposited diamond coatings on the all substrates have high purity. The upward shift of the peak position from standard diamond at $1332.4 \mathrm{~cm}^{-1}$ is attributed to a build-up of residual compressive stress in the film, and it can be used to roughly estimate the adhesion properties of the film to the substrates [23]. The residual stresses in the diamond coatings can be estimated using the equation [24]:

$$
\sigma=-0.567 \triangle v
$$

where, $\sigma$ is the biaxial stress of the coatings (GPa), $\Delta v$ is Raman shift of the diamond coatings from that of natural diamond $\left(1332.4 \mathrm{~cm}^{-1}\right)$, and a negative value corresponds to a compressive stress. According to Eq. (1), the residual stresses in diamond films deposited on conventional and gradient WC-10Co substrates are 3.29 and 2.27 GPa respectively, that is to say, the diamond film deposited on gradient WC-10Co has lower stress value. In general, the low stress level is beneficial to improve the adhesion between the film and the substrate. Therefore, it can be deduced that the diamond films deposited on gradient WC-10Co would offer higher adhesive strength. 


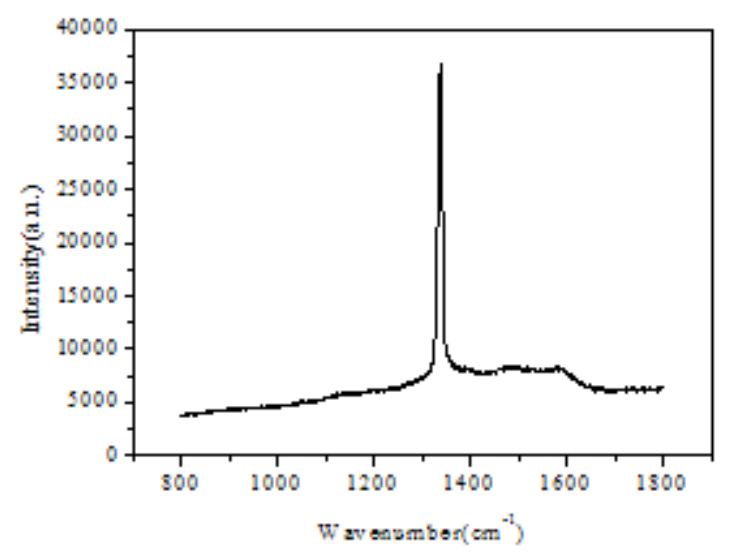

(a)

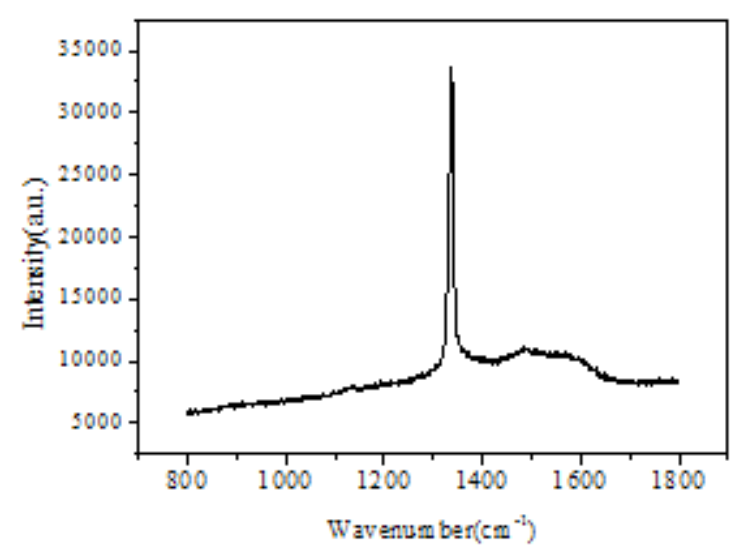

(b)

Fig.3 Raman spectrum of diamond films deposited on different substrates. (a) conventional WC-10Co and (b) gradient WC-10Co.

The adhesion of diamond coatings was further evaluated using the Rockwell $\mathrm{C}$ indentation method. Fig. 4 shows the results of the indentation tests on diamond coatings deposited on different substrates under a load of $980 \mathrm{~N}$. From this figure, it can be seen clearly that, for the diamond film deposited on conventional WC-10Co, a large flaking area of coating together with the etched substrate around the indentation is obvious, as demonstrated in Fig. 4a, which indicates a poor adhesion. Contrary, there is no obvious peeling area except the spallation area around the indentation on the diamond film deposited on gradient WC-10Co, as displayed in Fig. 4b. Therefore, it can be concluded that the adhesion of the diamond coating on the gradient WC-10Co substrate is higher than that of conventional WC-10Co.

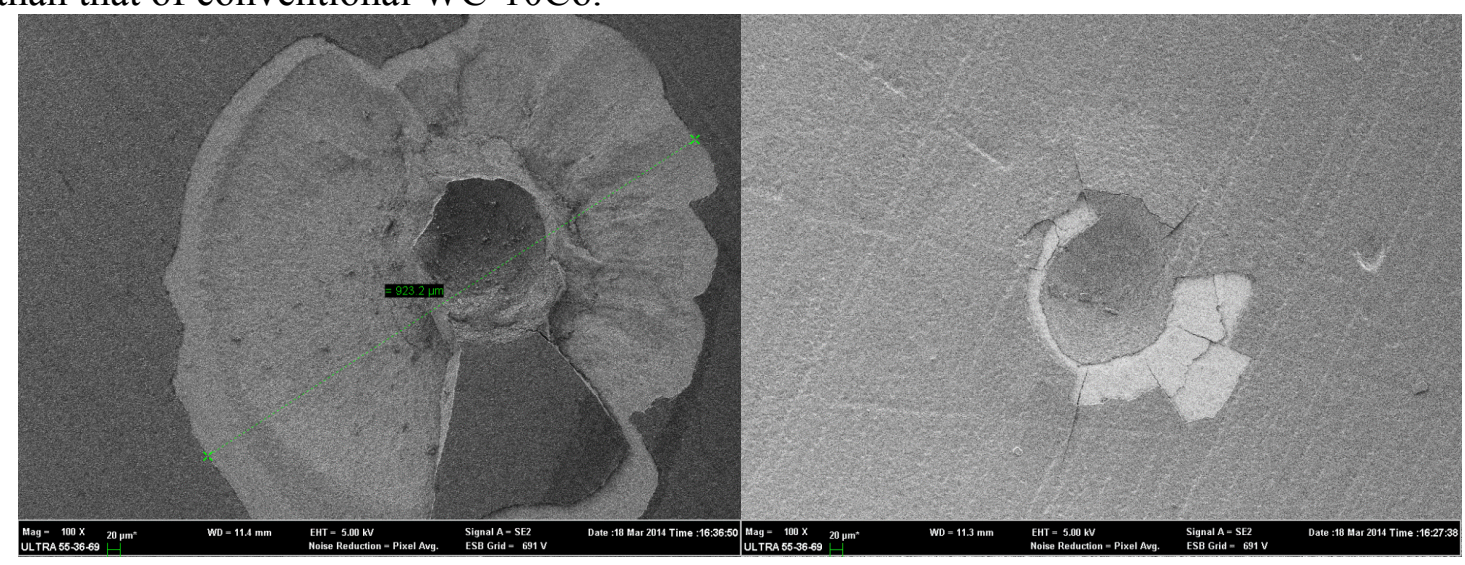

(a) (b)

Fig. 4 Rockwell indentation on diamond coating deposited for $6 \mathrm{~h}$ on different substrates pretreated with chemical etching. (a) conventional WC-10Co and (b) gradient WC-10Co.

\section{Discussion}

In the machining process, although diamond of diamond coated tools is in direct contact with the material to be machined, given the limited thickness of the film, mechanical stresses are transmitted to the WC-Co substrate. Therefore, besides the quality and adhesion of diamond coating, the mechanical properties of WC-Co substrate are also important factor influencing the final performance of diamond coated tools. Generally, the mechanical properties of WC-Co hardmetal are primarily dependent on Co content and WC grain size. With high Co content at fixed WC particle size, WC-Co has a higher strength and fracture toughness [25]. Based on this principle, if one can deposit diamond onto WC-Co substrate with high Co content, diamond coated tools would have extremely wear resistant while retaining high mechanical properties in the underlying WC-Co substrate. However, the adhesion of diamond films onto WC-Co substrates, as described in the 
introduction section, is strongly influenced by the surface Co content of the substrates. For the untreated WC-10Co substrate, during the process of HFCVD, Co will diffuse to the surface and dissolve carbon at high temperatures, resulting in the formation of amorphous carbon instead of diamond, which will seriously destroy the adhesion strength between diamond and substrate [26]. It is impossible to deposit adherent diamond films onto the untreated WC-10Co substrates, and surface cobalt must be removed.

Among the numerous pretreatment procedures, chemical etching is the simplest, and cheap, and was considered to be suitable for batch production. It has been proved that chemically etched WC-Co tool materials with Co binder less than $6 \mathrm{wt}$. \% show the high adhesive-bond strength to the diamond coating [6]. Unfortunately, the higher the Co content in WC-Co, the larger the distance between two adjacent WC particles (i.e. Co mean free path). After the etching, although the Co can be almost completely removed from the surface (as seen in Fig.1b), and the diamond films deposited on conventional WC-10Co have a good growth and a high purity (as shown in Fig. 2a and Fig.3a, respectively), etching will severely lower the bonding strength of the subsurface WC particles. In the presence of large stresses such as those encountered in indentation tests, flaking of the coating will occur by WC grain de-cohesion and consequent crack propagation in the Co-depleted layer of the carbide, resulting in a large flaking area of coating together with the etched substrate (as shown in Fig. 4a).

Different from the conventional WC-10Co, gradient WC-10Co has varied distributions of Co in different regions, namely, the surface layer is poor in Co while the core has the nominal Co content. In general, the surface Co content of substrates after etched depends not only on the etching agents and etching time, but also on the Co content of the original surface [6]. The lower the Co contents on surface of WC-Co, the smaller the Co mean free path, thus leading to a smaller etching channel during etching. As a result, at the same pretreatment condition, the etching depth and the Co content in surface layer of gradient WC-10Co etched are lower. During the deposition process, the presence of the Co in the substrate surface will strongly inhibit the growth of diamond, resulting in a lower diamond nucleation rates. Co content in surface layer of gradient WC-10Co etched are lower, accordingly the mean grain size of diamonds grown on gradient WC-10Co are slightly smaller than that of conventional WC-10Co. Furthermore, the lower Co content of etched surface will also decrease the thermal expansion coefficient of substrate, and then reduce the mismatch in the thermal expansion coefficients between diamond and WC-Co, leading to a lower stress value in the diamond film deposited on gradient WC-10Co. The combination of all these beneficial effects makes gradient WC-10Co possess high adhesion strength to diamond film. Considering that the core of substrate has a higher bending strength and fracture toughness, thus it can be expected that gradient WC-10Co would be a very promising substrate material for producing diamond coated tools.

\section{Conclusions}

In this paper, the results on the quality and adhesion characterization of diamond film, deposited on chemically treated functionally gradient WC-10wt. \%Co cemented carbide by HFCVD method, were reported. SEM and Raman spectroscopy results confirm that the diamond film deposited has a good growth and a high purity. Rockwell indentation tests reveal good adhesion of the diamond film. These improvements can be attributed to the unique microstructure of gradient WC-10Co. Application tests are in progress.

\section{Acknowledgements}

This work is supported by Shanghai Natural Science Foundation (No. 13ZR1401300).

\section{References}

[1] Gomez H, Durham D, Xiao XC, et al. Adhesion analysis and dry machining performance of 
CVD diamond coatings deposited on surface modified WC-Co turning inserts [J]. J. Mater. Process. Technol. 2012 (212) 523- 533

[2] Zhang JG, Wang XC, Shen B, et al. Effect of boron and silicon doping on improving the cutting performance of CVD diamond coated cutting tools in machining CFRP [J]. Int. J. Refract. Met. Hard Mater. 2013 (41) 285-292

[3] Cabral G, Reis P, Polini R, et al. Cutting performance of time-modulated chemical vapour deposited diamond coated tool inserts during machining graphite [J]. Diamond Relat. Mater. 2006 (15) 1753-8

[4] Polini R, Casadei F, D'Antonio P, et al. Dry turning of alumina/aluminum composites with CVD diamond coated Co-cemented tungsten carbide tools [J]. Surf. Coat. Technol. 2003 (166) 127-134

[5] Polini R. Chemically vapour deposited diamond coatings on cemented tungsten carbides: Substrate pretreatments, adhesion and cutting performance [J]. Thin Solid Films, 2006 (515)4-13

[6] Miao JQ, Song JH, Xue YD, et al. Effect of a two-step pretreatment method on adhesion of CVD diamond coatings on cemented carbide substrates [J]. Surf. Coat. Technol. 2004 (187)33-6

[7] Buck V, Deuerler F, Kluwe H, et al. Influence of chemical pretreatment of hardmetal substrates for diamond deposition [J]. Int. J. Refract. Met. Hard Mater. 2002 (20) 101-5.

[8] Haubner R, Köpf A, Lux B. Diamond deposition on hardmetal substrates after pre-treatment with boron or sulfur compounds [J]. Diamond Relat. Mater. 2002 (11) 555-561.

[9] Köpf A, Sommer M, Haubner R, Lux B. Diamond deposition on hardmetal substrates after pre-treatment with aluminium or aluminium compounds [J]. Diamond Relat. Mater. 2001 (10)790-796

[10]Tang W, Wang Q, Wang S, Lu F. A comparison in performance of diamond coated cemented carbide cutting tools with and without a boride interlayer [J]. Surf. Coat. Technol. 2002 (153) 298-303

[11] Xu F, Xu JH, Yuen MF, et al. Adhesion improvement of diamond coatings on cemented carbide with high cobalt content using PVD interlayer [J]. Diamond Relat. Mater. 2013 (34) $70-5$

[12]Lessiak M, Haubner R. Diamond coatings on hardmetal substrates with CVD coatings as intermediate layers [J]. Surf. Coat. Technol. 2013 (230) 119-123

[13] Xu ZQ, Lev L, Lukitsch M, Kumar A. Effects of surface pretreatments on the deposition of adherent diamond coatings on cemented tungsten carbide substrates [J]. Diamond Relat. Mater. 2007 (16) 461-6

[14] Vandierendonck K, Quaeyhaegens C, Nesladek M, et al. Study of the diamond deposition on cemented carbides containing $10 \mathrm{wt}$ \% Co with a tungsten intermediate layer [J]. Surf. Coat. Technol. 1995 (74-75) 819-826

[15]Haubner R, Kalss W. Diamond deposition on hardmetal substrates - Comparison of substrate pre-treatments and industrial applications [J]. Int. J. Refract. Met. Hard Mater. 2010 (28) 475-483

[16]Fischer U, Hartzell E, Akerman J. Cemented carbide body used preferably for rock drilling and mineral cutting. US patent no. 4743515; 1988.

[17]Liu Y, Du M, Zhang MY, et al. Growth of diamond coatings on functionally graded cemented carbides [J]. Int. J. Refract. Met. Hard Mater. 2015 (49) 307-313

[18]Fan P, Fang ZZ, Guo J. A review of liquid phase migration and methods for fabrication of functionally graded cemented tungsten carbide [J]. Int. J. Refract. Met. Hard Mater. 2013 (36)2-9.

[19] Wang X, Hwang KS, Koopman M, Fang ZZ, Zhang LH. Mechanical properties and wear resistance of functionally graded WC-Co [J]. Int. J. Refract. Met. Hard Mater. 2013 (36)46-51.

[20] Yuan YG, Ding JJ, Wang YK, Sun WQ. Fabrication of functionally gradient ultrafine-grained WC-Co composites [J]. Appl. Mech. Mater. 2013 (423-426)885-9. 
[21]Yuan YG, Ding JJ, Wang YK, et al. Optimization of process parameters for fabricating functionally gradient WC-Co composites [J]. Int. J. Refract. Met. Hard Mater. 2014 (43) 109-114

[22]Benarioua Y, Lesage J, Chicot D, Moisan M. Structure and hardness of diamond films deposited on WC-Co by CVD technique [J]. Surf. Coat. Technol. 2013 (227) 70-4

[23]Li YS, Tang Y, Yang Q, et al. Ultrathin W-Al dual interlayer approach to depositing smooth and adherent nanocrystalline diamond films on stainless steel [J]. ACS Appl. Mat. Interfaces, 2010 (2)335-8

[24]Ralchenko VG, Smolin AA, Pereverzev VG, et al. Diamond deposition on steel with CVD tungsten intermediate layer [J]. Diamond Relat. Mater. 1995 (4) 754-8

[25] Kim BK, Ha GH, Lee DW. Sintering and microstructure of nanophase WC/Co hardmetals [J]. J. Mater. Process. Technol. 1997 (63)317-21

[26]Inspektor A, Oles EJ, Bauer CE. Theory and practice in diamond coated metal-cutting tools [J]. Int. J. Refract. Met. Hard Mater. 1997 (15) 49-56 